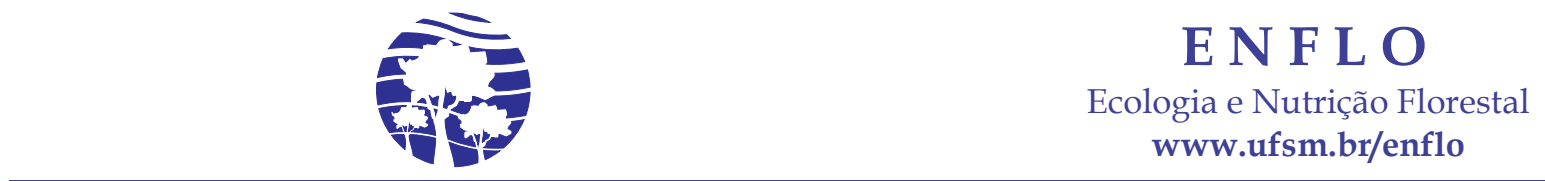

\title{
Produção de serapilheira e restituição de nutrientes em florestas secundárias do litoral paranaense $^{1}$
}

\author{
Thiago Woiciechowski²; Renato Marques ${ }^{3}$
}

\begin{abstract}
Resumo: Em seis áreas de florestas secundárias com distintas idades, sob domínio de Floresta Ombrófila Densa Submontana do Paraná, foram realizadas coletas mensais de serapilheira, em 25 coletores de $1 \mathrm{~m}^{2}$ suspensos distribuídos sistematicamente nas áreas de 1 ha cada; com o objetivo de estimar a produção de serapilheira: anual, estacional, pelas frações folhas, galhos, órgãos reprodutivos e miscelânea, e a quantidade de nutrientes restituídos. As florestas secundárias foram denominadas de FS, sendo FS-1 e FS-2 com 100 anos aproximadamente (mais desenvolvidas); FS-3 e FS-4 entre 60 e 80 anos (intermediárias); FS-5 entre 40 e 60 anos e FS-6 entre 20 e 30 anos (menos desenvolvidas). Após as quantificações da fitomassa houve a homogeneização e moagem para análises químicas de C, N, P, K, Ca e Mg. A produção anual ficou entre 5 e $10 \mathrm{Mg} \mathrm{ha}^{-1}$ ano $^{-}$ ${ }^{1}$ e foi observado diferença estatística na produção anual e estacional, sendo o verão e a primavera os períodos com as maiores taxas de deposição. A deposição anual não teve relação com a idade e com as estruturas fitossociológicas das florestas. A fração folhas foi responsável pelas maiores taxas e padrão de deposição nas áreas, porém a fração miscelânea contribuiu para o maior retorno de nutrientes no solo nas florestas mais desenvolvidas. A quantidade anual de nutrientes restituídos apresentou a sequência $\mathrm{C}>\mathrm{N}>\mathrm{Ca}>\mathrm{K}>\mathrm{Mg}>\mathrm{P}$ nas áreas, com exceção de FS-1, com maior teor de $\mathrm{Mg}$ em relação ao $\mathrm{K}$. A sequência no aporte anual de nutrientes foi FS-1=FS-2>FS-5>FS-6>FS-4>FS-3 concluindo que as florestas mais desenvolvidas retornaram mais nutrientes para o solo.
\end{abstract}

Palavras-chave: Fitomassa; Ciclagem de Nutrientes; Floresta Ombrófila Densa; Sucessão Florestal.

\section{Litterfall and restitution of nutrientes in secondary forests of the coast Paraná state}

\begin{abstract}
Monthly collections of litterfall were collected in secondary forest areas with different ages under the control of Dense Ombrophylous Submontane Forest in Paraná state 25 collectors of $1 \mathrm{~m}^{2}$ suspended systematically distributed in 1 ha each; with the objective of estimating the production of litter: Annual, seasonal, by fractions leaves, twigs, reproductive organs and remains, and the amount of nutrients restored. Secondary forests were called SF, with SF-1 and SF-2 being approximately 100 years old (more developed); SF-3 and FS-4 between 60 and 80 years (intermediate); SF- 5 between 40 and 60 years and SF-6 between 20 and 30 years (less developed). After the quantifications of the phytomass, homogenization and milling were performed for chemical analyzes of $\mathrm{C}, \mathrm{N}, \mathrm{P}, \mathrm{K}, \mathrm{Ca}$ and $\mathrm{Mg}$. The annual production was between 5 and $10 \mathrm{Mg} \mathrm{ha}^{-1} \mathrm{year}^{-1}$ and a statistical difference was observed in annual and seasonal production, with summer and spring being the highest deposition rates. The annual deposition had no relation with the age and phytosociological structures of the forests. The leaves fraction was responsible for the higher rates and pattern of deposition in the areas, but the miscellaneous fraction contributed to the higher nutrient return in the soil in the more developed forests. The annual amount of nutrients returned had the sequence $\mathrm{C}>\mathrm{N}>\mathrm{Ca}>\mathrm{K}>\mathrm{Mg}>\mathrm{P}$ in the areas, with the exception of FS-1, with a higher content of $\mathrm{Mg}$ in relation to $\mathrm{K}$. The sequence in the annual nutrient supply was FS- $1=$ FS-2>FS-5>FS-6>FS-4>FS-3 concluding that more developed forests returned more nutrients to the soil.
\end{abstract}

Keywords: Litterfall; Nutrient Cycling; Brazilian Atlantic Forest; Forest Succession.

\footnotetext{
${ }^{1}$ Recebido em 27.05.2017 e aceito para publicação como artigo científico em 21.09.2017.

${ }^{2}$ Engenheiro Florestal, Dr. Professor adjunto, Universidade Estadual de Mato Grosso do Sul - UEMS, campus de Aquidauana/MS. E-mail: <thiagowoi@uems.br>.

${ }^{3}$ Engenheiro Florestal, Dr. Professor associado, Programa de Pós-graduação em Engenharia Florestal, Universidade Federal do Paraná UFPR, Curitiba/PR. E-mail: <rmarques@ufpr.br>.
} 


\section{Introdução}

A Floresta Atlântica é o terceiro maior bioma do Brasil e, o estado do Paraná mantém 36,5\% desse bioma na Serra do Mar, constituindo o segundo maior fragmento conservado do país, com aproximadamente 509 mil ha de extensão (RIBEIRO et al., 2009). No passado, ocorreram inúmeros distúrbios em florestas primárias da Floresta Atlântica do litoral do Paraná devido ao uso intensivo do solo para agropecuária. Após o abandono destas áreas, as florestas naturais resultantes do processo de regeneração, denominadas de florestas secundárias, sofreram transformações ao longo da sucessão, como: o aumento do desenvolvimento estrutural, provocadas pela competição entre as árvores por nutrientes e luz, pelo maior ou menor número de espécies arbóreas pioneiras e pelo aumento em altura e diâmetro do tronco de árvores em crescimento, conduzindo a produções diferenciadas de serapilheira (JANZEN, 1980; LEIGH, 1999). A medida que a floresta secundária envelhece sua estrutura se torna mais complexa, ficando distinto o processo de deposição de serapilheira e a consequente liberação de nutrientes.

A produção de serapilheira é um parâmetro importante na dinâmica de uma floresta e funciona como um indicador de entradas e saídas de nutrientes e, de matéria orgânica, formando uma camada superficial no solo composta por folhas, ramos, órgãos reprodutivos e detritos (COSTA et al., 2010). As variações no padrão de produção de serapilheira são causadas por diversos fatores, entre eles: clima, composição florística, estágio sucessional, idade, condições do solo, gradiente de altitude, bem como a presença e a intensidade dos diversos fatores ambientais como a seca, geada, poluição e queimadas (DELITTI, 1984; DOMINGOS et al., 1990; LEITÃO FILHO et al., 1993; BRITEZ, 1994).

Em florestas tropicais, a quantidade de serapilheira depositada sobre o solo, em geral, varia de 4 a $25 \mathrm{Mg} \mathrm{ha}^{-1} \mathrm{ano}^{-1}$, apresentando grande amplitude na produção total (BRAY e GORHAM, 1964; PROCTOR, 1983; HAAG et al., 1985; BRITEZ, 1994; PINTO e MARQUES, 2003). As diferentes frações que compõem a serapilheira depositada são compostas, geralmente, de 60 a $80 \%$ de folhas e de 1 a $15 \%$ de ramos (BRAY e GORHAM, 1964). A fração folhas é a principal fração na serapilheira depositada, e em muitos casos, condicionam o padrão geral de deposição sendo responsáveis pelo retorno da maior quantidade de nutrientes ao solo, tendo valores próximos a $71 \%$ na produção total para florestas tropicais. (O'NEILL e De ANGELIS, 1980; CALDEIRA et al., 2007).

A concentração e o conteúdo de nutrientes na serapilheira variam em função do tipo de solo, da vegetação, da densidade populacional, da habilidade da espécie em absorver, utilizar e redistribuir os nutrientes, do habitat natural e da idade das árvores (NEVES et al., 2001). As tipologias florestais possuem um padrão na distribuição do aporte de serapilheira ao longo do ano, que pode ser influenciado por diversos fatores como: fenologia das espécies presentes, condições meteorológicas, estágio sucessional e posição no relevo (GIÁCOMO, 2009). Embora existam diversos estudos relacionados ao aporte de nutrientes na Floresta Atlântica (CALDEIRA et al., 2008; CALVI et al., 2009; SILVA e VILLELA, 2015; SLOBODA et al., 2017), são poucos os que relatam a transferência de nutrientes em florestas secundárias com diferentes idades.

No final da década de 60, no Brasil, iniciaram-se os estudos de ciclagem de nutrientes em florestas tropicais. Apesar da diversidade de estudos há ainda a necessidade de investigação sobre ciclagem de nutrientes em florestas tropicais brasileiras, especialmente, na Floresta Atlântica. Alguns estudos importantes na Floresta Ombrófila Densa da Mata Atlântica referem-se especialmente a deposição e decomposição da serapilheira (HINKEL, 2002; PINTO et al., 2003; BOEGER et al., 2005; PROTIL, 2006; ROCHA, 2006; SCHEER et al., 2008; DICKOW et al., 2012; BIANCHIN et al., 2016; SLOBODA et al., 2017).

Perante o exposto, visando a necessidade de busca pelos processos de ciclagem de nutrientes 
em florestas tropicais e, considerando diversos fatores atuantes na dinâmica biogeoquímica de florestas com vistas a conservação de áreas naturais, este estudo teve como objetivos estimar a produção anual, estacional e por diferentes frações de serapilheira, bem como o retorno de $\mathrm{C}, \mathrm{N}, \mathrm{P}, \mathrm{K}, \mathrm{Ca}$ e $\mathrm{Mg}$ por frações e anual em seis áreas de formações florestais secundárias com distintas idades e estruturas fitossociológicas na Floresta Ombrófila Densa Submontana, em Antonina, Paraná.

\section{Material e métodos}

Área de estudo

A área de estudo está localizada na Reserva Natural do Rio Cachoeira (RNRC), uma unidade de conservação particular de propriedade da organização não governamental Sociedade de Pesquisa em Vida Selvagem e Educação
Ambiental (SPVS), inserida na Área de Proteção Ambiental (APA) de Guaraqueçaba, em Antonina, litoral do Paraná (Figura 1). A RNRC está inserida na Floresta Atlântica, cobertura vegetal da região serrana do estado do Paraná, sendo classificada como Floresta Ombrófila Densa Submontana (IBGE, 2012), em estágio secundário de regeneração (FERRETI e BRITEZ, 2005) situada nas encostas dos planaltos e/ou serras com altitude variáveis entre 50 e $400 \mathrm{~m}$ de altitude. A área da RNRC é de $8.635,90$ ha e os pontos extremos têm como coordenadas geográficas as latitudes $25^{\circ} 24^{\prime}$ $25^{\circ} 41^{\prime} \mathrm{S}$ e longitudes de $48^{\circ} 64^{\prime}-48^{\circ} 74^{\prime} \mathrm{W}$. O tipo climático da região é o subtropical úmido mesotérmico (Cfa), definido por Köppen e a precipitação média do mês mais seco é $60 \mathrm{~mm}$ (SPVS, 2005). Os dados meteorológicos da área, durante o período do estudo (Figura 2), foram coletados em estação meteorológica distante em aproximadamente $10 \mathrm{~km}$.

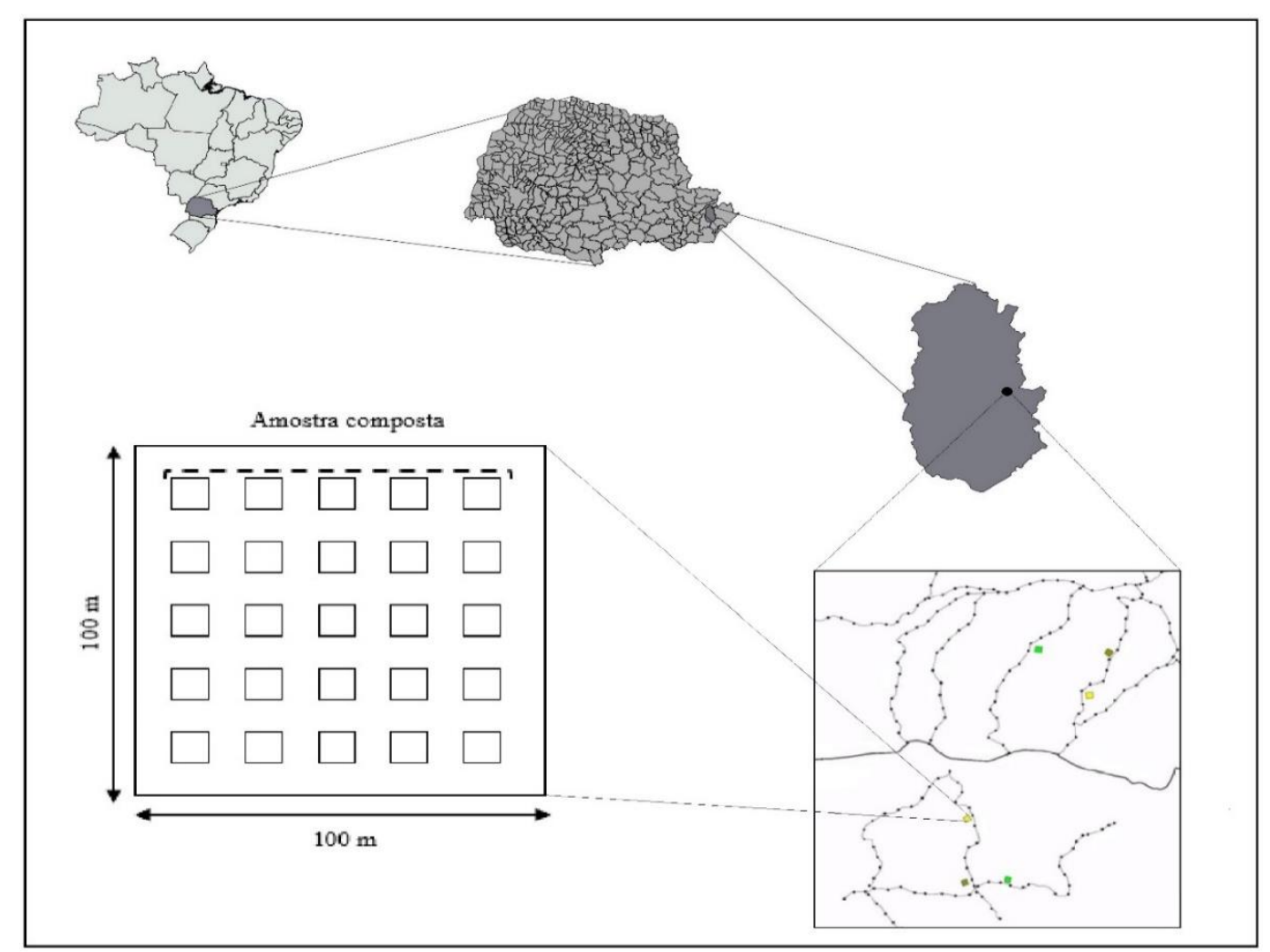

Figura 1 - Área de estudo, alocação das parcelas, subparcelas e distribuição sistemática dos coletores de serapilheira em seis áreas de formações secundárias com diferentes idades e estruturas fitossociológicas, de Floresta Ombrófila Densa Submontana em Antonina, PR

Figure 1 - Study area, allocation of plot, subplots and systematic distribution of litterfall collectors in six areas of secondary formations with different ages and phytosociological structures, of the Brazilian Atlantic forest. 


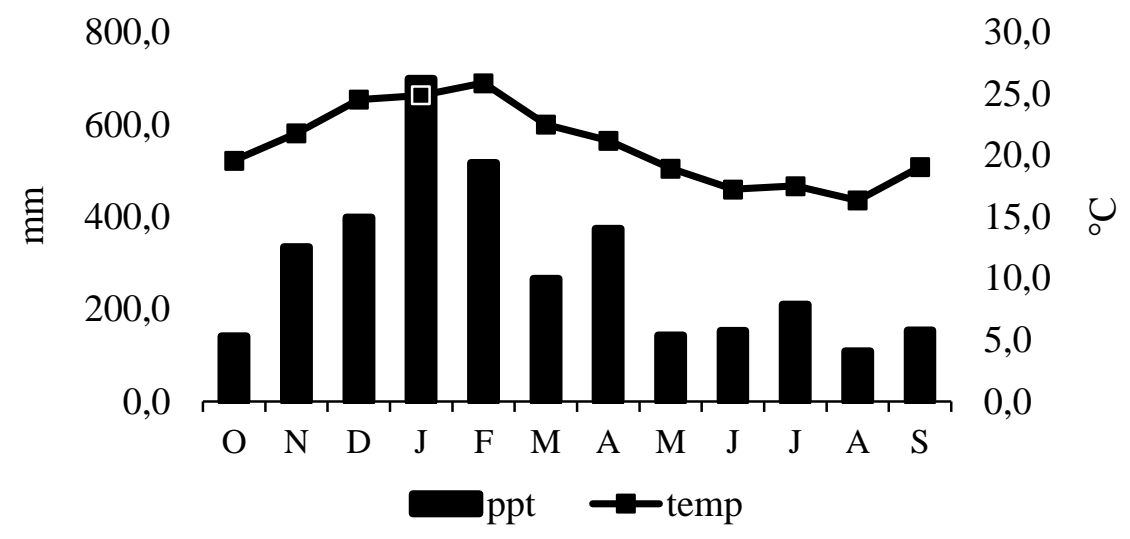

Figura 2 - Precipitação e temperatura médias nos anos de estudo (Out/2009-Set/2010), da estação meteorológica de Antonina, PR. Dados cedidos pelo Sistema Meteorológico do Paraná (2014).

Figure 2 - Average precipitation and temperature in the years of study (Oct /2009-Sep/2010), from the Antonina, Paraná state meteorological station. Data provided by the Paraná Meteorological System (2014).

Os solos predominantes nas áreas deste estudo pertencem à ordem dos Cambissolos (SPVS, 2005). Os atributos químicos dos solos em cada floresta secundária são indicados na Tabela 1. De acordo com a classificação dos atributos químicos pela Sociedade Brasileira de
Ciência do Solo (SBCS), os solos das áreas são ácidos e distróficos, a concentração de $\mathrm{C}$ no solo foi classificada como alta e os valores dos nutrientes estavam em concentrações muito baixa ou baixa na camada de $0-20 \mathrm{~cm}$.

Tabela 1 - Atributos químicos ${ }^{1}$ dos solos das florestas secundárias em estudo, na camada de 0-20 cm, em Floresta Ombrófila Densa, Antonina, PR.

Table 1 - Chemical attributes ${ }^{1}$ of the soils in the secondary forests studied, in 0-20 cm layers, in the Brazilian Atlantic Forest

\begin{tabular}{cccccccc}
\hline $\begin{array}{c}\text { Florestas } \\
\text { secundárias }\end{array}$ & $\begin{array}{c}\mathbf{p H} \\
\mathrm{CaCl}_{2}\end{array}$ & $\begin{array}{c}\mathbf{C} \\
\mathrm{g} \mathrm{dm}^{-3}\end{array}$ & $\begin{array}{c}\mathbf{P} \\
\mathrm{mg} \mathrm{kg}^{-1}\end{array}$ & $\mathbf{C a}$ & $\begin{array}{c}\mathbf{M g} \\
----\mathrm{cmol}_{\mathrm{c}} \mathrm{dm}^{-3}----\end{array}$ & $\begin{array}{c}\mathbf{K} \\
\%\end{array}$ \\
\hline FS-1 & 3,6 & 30,9 & 7,0 & 0,5 & 0,6 & 0,1 & 12,7 \\
FS-2 & 3,5 & 25,2 & 3,0 & 0,2 & 0,3 & 0,1 & 6,0 \\
FS-3 & 2,9 & 32,0 & 4,1 & 0,3 & 0,2 & 0,1 & 6,3 \\
FS-4 & 3,6 & 19,6 & 7,7 & 0,7 & 0,4 & 0,2 & 10,3 \\
FS-5 & 3,3 & 36,4 & 4,8 & 0,2 & 0,2 & 0,1 & 3,8 \\
FS-6 & 3,4 & 28,7 & 9,3 & 0,4 & 0,3 & 0,1 \\
\hline
\end{tabular}

${ }^{1}$ Todos os valores formam obtidos seguindo a metodologia analítica descrita por Marques e Motta (2003); V= saturação por bases.

Amostragem e coleta da serapilheira

Para este estudo, foram selecionadas seis áreas de florestas secundárias (FS) com diferentes idades e estruturas fitossociológicas denominadas: FS-1; FS-2; FS-3; FS-4; FS-5 e FS-6 de acordo com a ordem cronológica decrescente (Figura 1). As áreas FS-1 e FS-2 são florestas secundárias mais desenvolvidas, já as áreas FS-3 e FS-4 são consideradas florestas secundárias intermediárias e por fim, as áreas FS-5 e FS-6 compõem as florestas secundárias menos desenvolvidas (Tabela 2). 
Tabela 2 - Parâmetros fitossociológicos ${ }^{1}$ de seis áreas de floresta secundária com diferentes idades e estruturas fitossociológicas, em Floresta Ombrófila Densa Submontana do litoral do PR. Dados não publicados.

Table 2 - Phytosociological parameters ${ }^{1}$ of six secondary forest areas with different ages and phytosociological structures, in Brazilian Atlantic forest. Unpublished data.

\begin{tabular}{|c|c|c|c|c|c|c|c|c|}
\hline $\begin{array}{l}\text { Floresta } \\
\text { secundária }\end{array}$ & Idade & $\mathbf{N}^{\circ}$ Ind. & $\begin{array}{l}\text { Área } \\
\text { basal }\end{array}$ & $\mathbf{h}$ & $\mathbf{H}^{\prime}$ & $\mathbf{J}$ & Espécies com maior IVI & IVI \\
\hline FS-1 & $>100$ & 1711 & 37 & 8 & 4,2 & 0,88 & $\begin{array}{c}\text { Psychotria nuda } \\
\text { Hyeronima alchorneoides }\end{array}$ & $\begin{array}{l}45 \\
29\end{array}$ \\
\hline FS-2 & $>100$ & 1753 & 37 & 8 & 3,9 & 0,79 & $\begin{array}{l}\text { Psychotria nuda } \\
\text { Marlierea tomentosa }\end{array}$ & $\begin{array}{l}22 \\
20\end{array}$ \\
\hline FS-3 & $60-80$ & 1693 & 35 & 7 & 3,5 & 0,70 & $\begin{array}{c}\text { Psychotria nuda } \\
\text { Hyeronima alchorneoides }\end{array}$ & $\begin{array}{l}30 \\
16\end{array}$ \\
\hline FS-4 & $60-80$ & 2094 & 36 & 8 & 3,7 & 0,74 & $\begin{array}{c}\text { Psychotria nuda } \\
\text { Hyeronima alchorneoides }\end{array}$ & $\begin{array}{l}21 \\
18\end{array}$ \\
\hline FS-5 & $40-60$ & 1888 & 34 & 9 & 3,5 & 0,76 & $\begin{array}{c}\text { Pera glabrata } \\
\text { Amaioua guianensis }\end{array}$ & $\begin{array}{l}34 \\
21\end{array}$ \\
\hline FS-6 & $20-30$ & 2191 & 25 & 8 & 2,7 & 0,62 & $\begin{array}{l}\text { Myrsine coriacea } \\
\text { Tibouchina pulchra }\end{array}$ & $\begin{array}{l}58 \\
47 \\
\end{array}$ \\
\hline
\end{tabular}

${ }^{1}$ Idade, em anos; $\mathrm{N}^{\circ}$ Ind., número de indivíduos com diâmetro a altura do peito $\geq 10 \mathrm{~cm}$; Área basal, $\mathrm{em} \mathrm{m}^{2} / \mathrm{ha}$; $\hbar$, altura média de árvores em m; H', índice de diversidade de espécies de Shannon; J, índice de equabilidade de Pielou; IVI, índice de valor de importância, em \%.

Cada área de floresta secundária possuía 100 subparcelas de $100 \mathrm{~m}^{2}$ cada, onde foram alocados 25 coletores suspensos, feitos de PVC com $1 \mathrm{~m}^{2}$ de área e tela de nylon de $2 \mathrm{~mm}$, de forma sistematizada nas subparcelas (Figura 1). As coletas de serapilheira foram realizadas mensalmente entre outubro de 2009 e setembro de 2010. O agrupamento dos coletores formou amostras compostas por estarem alinhados e distribuídos ordenadamente acompanhando a declividade do terreno, a fim de tornar a amostragem mais homogênea e com isso reduzir a variabilidade (BIANCHIN et al., 2016). A produção mensal de serapilheira por hectare foi estimada através da equação citada por Bianchin et al. (2016) adaptada de Toledo e Pereira, (2004):

$$
P M S=\frac{\sum P S \times 10000}{A C \times n}
$$

Em que: PMS = produção mensal de serapilheira, em $\mathrm{kg}$ $\mathrm{ha}^{-1} ; \mathrm{PS}=$ produção de serapilheira em cada coletor, em $\mathrm{kg} ; \mathrm{AC}=$ área do coletor, em $\mathrm{m}^{2} \mathrm{e} \mathrm{n}=$ número de coletores agrupados.

O material coletado foi acondicionado em sacos plásticos identificados, posteriormente colocados para secar ao ar livre e transferidos para sacos de papel e, novamente, secos em estufa a $60 \pm 5^{\circ} \mathrm{C}$ durante 72 horas. Em seguida, a serapilheira foi separada nas seguintes frações: fração folhas (folhas de espécies identificadas e não identificadas); fração galhos (galhos inferiores a $2 \mathrm{~mm}$ de diâmetro); fração órgãos reprodutivos (flores, frutos e sementes); fração miscelânea (material de origem animal e vegetal que sobrou da triagem e passou por uma peneira de malha $9 \mathrm{~mm}$ ) e pesados em balança de precisão de $0,01 \mathrm{~g}$. Não foi considerada a fração cascas, pelo fato de não ter sido representativa em todos os coletores das áreas nos períodos avaliados. Posteriormente, as amostras foram homogeneizadas e moídas em moinho de facas para a análise química.

Nas frações de serapilheira depositada foram determinados os teores de carbono (C), nitrogênio $(\mathrm{N})$, fósforo $(\mathrm{P})$, potássio $(\mathrm{K})$, cálcio (Ca) e magnésio ( $\mathrm{Mg}$ ) no Laboratório de Biogeoquímica da Universidade Federal do Paraná. Para a determinação dos teores de C e N foram pesados entre 15 e $20 \mathrm{mg}$ do material finamente moído em moinho de bola Fritsch e incinerado em analisador Elementar de CHNOS Vario EL III. Para a determinação dos teores de macronutrientes, utilizou-se a metodologia da digestão seca, descrita por Martins e Reissmann 
(2007). As determinações dos nutrientes foram realizadas por espectrometria de emissão atômica com plasma induzido em Varian 720 ES IIC “Opctical Emissão Spectrometer”. O aporte dos nutrientes foi calculado multiplicando a concentração dos nutrientes pela deposição, em cada fração.

Análise estatística

Os dados foram submetidos ao teste de homogeneidade das variâncias dos tratamentos utilizando-se o teste de Bartlett. Posteriormente, verificada a normalidade, os dados foram submetidos à análise de variância (ANOVA) e, em seguida, as médias foram comparadas entre si pelo teste de Tukey, com probabilidade de 95 e 99\% utilizando o software Assistat@ (SILVA e AZEVEDO, 2002).

Para verificar como a serapilheira total se deposita em diferentes estações do ano e frações, foram realizadas ANOVAS fatorais, sendo o primeiro fator formado pelas florestas secundárias com seis níveis e o segundo fator, as estações do ano e frações de serapilheira, com quatro níveis cada, respectivamente. Por fim, na avaliação dos teores de nutrientes, as florestas secundárias foram comparadas entre si, dentro de cada fração, utilizando como repetições as estações do ano.

\section{Resultados e Discussão}

Produção anual e frações da serapilheira depositada

A produção total de serapilheira em cada estação do ano variou significativamente entre as áreas (Tabela 3). A maior deposição anual foi para a área FS-5, seguida de FS-2 estatisticamente superiores a FS-4, demonstrando que não houve relação de acréscimo ou decréscimo na produção total de serapilheira nas formações secundárias em decorrência da idade e, logo, esta variável não foi um fator de diferenciação na produção de serapilheira entre florestas secundárias deste estudo. A produção de serapilheira total ficou estimada entre 4,9 a 10,1 Mg ha-1 $\mathrm{ano}^{-1}$ nas áreas. Especificamente, na Floresta Ombrófila Densa Atlântica, os estudos já realizados estimaram quantidades entre 3 a $14 \mathrm{Mg} \mathrm{ha}^{-1}$ ano $^{-1}$, porém, foram encontrados valores de 5,2 e 8,4 $\mathrm{Mg} \mathrm{ha}^{-1}$ $\mathrm{ano}^{-1}$ nos trabalhos em áreas próximas as deste estudo (ROCHA, 2006; DICKOW et al., 2012; BIANCHIN et al., 2016; SLOBODA et al., 2017).

Tabela 3 - Produção total $\left(\mathrm{kg} \mathrm{ha}^{-1}\right)$ de serapilheira por estação do ano em seis áreas de formações secundárias com diferentes idades e estruturas fitossociológicas, de Floresta Ombrófila Densa Submontana em Antonina, PR

Table 3 - Total production $\left(\mathrm{kg} \mathrm{ha}^{-1}\right)$ of litterfall by season at areas of secondary formations with different ages and phytosociological structures, of the Brazilian Atlantic forest.

\begin{tabular}{ccccccc}
\hline \multirow{2}{*}{ Estação do ano } & \multicolumn{5}{c}{ Florestas secundárias } \\
\cline { 2 - 6 } & FS-1 & FS-2 & FS-3 & FS-4 & FS-5 & FS-6 \\
\hline Primavera & $2744 \mathrm{abA} *$ & $3321 \mathrm{aA}$ & $2333 \mathrm{bcA}$ & $1795 \mathrm{cA}$ & $2806 \mathrm{abB}$ & $2319 \mathrm{bcA}$ \\
Verão & $2436 \mathrm{bA}$ & $2378 \mathrm{bB}$ & $2223 \mathrm{bAB}$ & $2123 \mathrm{bA}$ & $5062 \mathrm{aA}$ & $2642 \mathrm{bA}$ \\
Outono & $1108 \mathrm{abB}$ & $1223 \mathrm{abC}$ & $1481 \mathrm{aBC}$ & $528 \mathrm{bB}$ & $963 \mathrm{abC}$ & $1281 \mathrm{abB}$ \\
Inverno & $1046 \mathrm{bB}$ & $2052 \mathrm{aB}$ & $1053 \mathrm{abC}$ & $493 \mathrm{bB}$ & $1281 \mathrm{abC}$ & $687 \mathrm{bB}$ \\
\hline Total & $7334 \mathrm{bc}$ & $8974 \mathrm{ab}$ & $7090 \mathrm{bc}$ & $4939 \mathrm{c}$ & $10112 \mathrm{a}$ & $6929 \mathrm{bc}$ \\
\hline
\end{tabular}

*Médias maiúsculas seguidas pela mesma letra na coluna e minúsculas na linha não diferem estatisticamente entre si pelo teste de Tukey a $1 \%$ de probabilidade.

Os resultados da deposição total de serapilheira corroboram com $\mathrm{o}$ fato de ocorrência de maior produção em áreas jovens com abundância de espécies pioneiras, principalmente em FS-5 (MEGURO et al., 1979; LEITÃO FILHO et al., 1993; OLIVEIRA e 
NETO 1999). Entretanto, embora as espécies pioneiras apresentem altos padrões de produtividade, a abundância dessas espécies em vegetações em estágio inicial de sucessão ecológica parece não constituir o principal fator determinante de altas taxas de produtividade, podendo ser menos importantes que o tamanho e o porte do dossel na determinação da produção total da serapilheira (SONGWE et al., 1988). Ainda, há a estabilidade da deposição da serapilheira, em decorrência da produção primária, em florestas mais avançadas devido ao avanço da sucessão secundária (BRAY e GORHAM, 1964).

A maior taxa de deposição ocorreu no período do verão e primavera sendo estatisticamente superior as estações outono e inverno, exceto para FS-2 no inverno. Esse fato pode estar relacionado às variáveis meteorológicas que favorecem o aumento da deposição nos períodos de maior precipitação e temperatura do ano (SILVA e BRITEZ, 2005). Silva (1984); Silva e Britez (2005) relataram a ocorrência de picos de deposição foliar atribuído aos períodos mais favoráveis de crescimento, com maior precipitação e temperatura. Esta tendência de maior deposição nas estações mais quentes e chuvosas, especificamente em formações de Floresta Ombrófila Densa, está ligada diretamente às condições meteorológicas por ser uma estratégia evolutiva das plantas, no sentido de renovar suas folhas no período mais favorável ao crescimento, contribuindo assim para o retorno de nutrientes ao solo e para a sua redisponibilização às plantas em crescimento (JACKSON, 1978). De acordo com Gomes et al. (2010) e Bianchin et al. (2016) houve uma correlação positiva da precipitação com a deposição de serapilheira em estudos na Mata Atlântica, respectivamente em fragmentos florestas em Teresópolis, RJ, e em florestas secundárias em estágios intermediários e mais desenvolvidos, em Antonina, PR. Além disso, um comportamento aleatório foi encontrado por Dickow et al. (2012) na deposição da serapilheira entre áreas com diferentes estágios de sucessão em Floresta Ombrófila Densa Submontana, em Antonina, PR em virtude das variações climáticas num período de três anos em contraposição com às diferenças da vegetação.

A idade nas diferentes áreas de florestas secundárias influenciou na deposição de serapilheira por frações (Tabela 4). As áreas FS2 e FS-5 foram superiores na deposição foliar em relação aos demais florestas devido a quantidade total que foi produzida no período. Não houve uma tendência clara na deposição de galhos e órgãos reprodutivos entre as florestas secundárias, apenas maior deposição de sementes em FS-6 e, por outro lado, a deposição de miscelânea não foi significativa para as áreas.

Foram observadas diferenças estatísticas entre as frações de serapilheira produzidas nas áreas de floresta secundária. A deposição de folhas foi significativamente superior as demais frações em todas as áreas. $\mathrm{O}$ padrão foi similar na deposição de frações nas florestas mais desenvolvidas. Nas áreas intermediárias, houve variação entre a deposição de galhos e miscelânea. E na área FS-6, a deposição de órgãos reprodutivos se igualou as frações galhos e miscelânea diferentemente de FS-5 em que esta fração foi inferior estatisticamente.

O percentual de folhas foi maior que $70 \%$ do total da produção anual em todas as formações, com exceção de FS-4 (59\% da contribuição de folhas). Os valores percentuais da fração folhas corroboram com os valores estabelecidos por O' Neill e De Angelis (1980), próximos a 71\% para florestas tropicais. Pereira et al. (2008) em um fragmento de Floresta Atlântica, localizado em uma encosta da Ilha da Marambaia, RJ verificaram que a fração folhas foi a que mais contribuiu no aporte de serapilheira representando 66\% do total aportado; Dickow et al. (2012) em formações secundárias em estágios inicial, médio e avançado da Mata Atlântica do litoral paranaense, ressaltaram que as folhas foram responsáveis por 77, 75 e $68 \%$ do total da serapilheira, respectivamente. A variação na deposição de galhos nas diferentes florestas secundárias ocasiona dois aspectos. $\mathrm{O}$ primeiro refere-se que em áreas mais jovens, o avanço da sucessão secundária induz o estabelecimento de espécies longevas na estrutura da floresta, que 
geralmente possuem mais galhos finos para serem renovados. De outra forma, as áreas com idade avançada, com o dossel mais fechado e sombreamento da parte inferior dos fustes, induz a queda dos galhos havendo maior deposição de galhos e folhas da parte inferior das copas, como resposta à diminuição de luminosidade nos estratos inferiores da floresta (BIANCHIN et al., 2016).

A produção de miscelânea e de material reprodutivo em uma mesma tipologia florestal podem ser muito variáveis ao longo de um ano ou um período. Deste modo, estas frações podem depender das condições abióticas locais, da composição, taxas de decomposição, da florística e da demografia de cada espécie (DINIZ e PAGANO, 1997). A maior produção de órgãos reprodutivos na FS-6 provavelmente está ligada a fenologia e ao ciclo reprodutivo das espécies na deposição nesta área e certamente contribuiu para a redução do percentual da fração folhas.

Tabela 4 - Produção anual de serapilheira por frações, em seis áreas com diferentes idades e estruturas fitossociológicas em floresta secundária de Floresta Ombrófila Densa Submontana em Antonina, PR.

Table 4 - Annual production of litterfall by fractions and species, in areas sites with different ages and phytosociological structures in secondary forest of the Brazilian Atlantic forest.

\begin{tabular}{ccccccc}
\hline \multirow{2}{*}{ Frações de serapilheira } & \multicolumn{5}{c}{ Florestas secundárias } \\
\cline { 2 - 7 } & FS-1 & FS-2 & \multicolumn{7}{c}{ FS-3 } & FS-4 & FS-5 \\
\cline { 2 - 7 } & \multicolumn{5}{c}{ Serapilheira produzida $\left(\mathrm{kg} \mathrm{ha}^{-1} \mathrm{ano}^{-1}\right)$} \\
\hline Folhas & $5242 \mathrm{aAB} *$ & $6677 \mathrm{aA}$ & $5221 \mathrm{aAB}$ & $2956 \mathrm{aC}$ & $7772 \mathrm{aA}$ & $4885 \mathrm{aB}$ \\
Galhos & $1063 \mathrm{bAB}$ & $1075 \mathrm{bAB}$ & $499 \mathrm{cB}$ & $1419 \mathrm{bA}$ & $982 \mathrm{bB}$ & $694 \mathrm{bB}$ \\
Órgãos reprodutivos & $48 \mathrm{cB}$ & $203 \mathrm{cB}$ & $310 \mathrm{cAB}$ & $78 \mathrm{cB}$ & $311 \mathrm{cAB}$ & $549 \mathrm{bA}$ \\
Miscelânea & $981 \mathrm{bA}$ & $1018 \mathrm{bA}$ & $1060 \mathrm{bA}$ & $502 \mathrm{cA}$ & $1046 \mathrm{bA}$ & $808 \mathrm{bA}$ \\
\hline Total & 7334 & 8974 & 7090 & 4934 & 10112 & 6929 \\
\hline
\end{tabular}

*Médias maiúsculas seguidas pela mesma letra na linha e minúsculas na coluna não diferem estatisticamente entre si pelo teste de Tukey a $1 \%$ de probabilidade.

Teor e aporte de nutrientes na serapilheira depositada

A análise estatística mostrou diferenças significativas nos teores de nutrientes em cada fração de serapilheira depositada nas florestas secundárias. As concentrações de $\mathrm{C}$ foram diferentes estatisticamente na fração órgãos reprodutivos. A concentração de $\mathrm{N}$ foi significativa em todas as frações. Já as concentrações de $\mathrm{Ca}$, apenas tiveram significância na fração folhas; $\mathrm{P}$ e $\mathrm{K}$ com diferença significativa nos galhos; e, $\mathrm{P}$ variou nos órgãos reprodutivos e miscelânea (Tabela 5).

Em geral, a concentração de $\mathrm{C}$ nas frações não apresentou comportamento padrão, uma vez que o nutriente é mais estável na parte aérea e, por conseguinte, seria a variável que menos contribuiria na dissimilaridade das frações em relação ao teor de nutrientes. Dickow (2012) observou maior valor de $\mathrm{C}$ em uma floresta secundária intermediária no litoral do Paraná para todas as frações de serapilheira, entretanto, neste estudo, o teor de $\mathrm{C}$ foi significativo apenas na fração órgãos reprodutivos em FS-6 provavelmente devido à maior deposição da fração no período avaliado.

$\mathrm{O}$ teor de $\mathrm{N}$ nas frações aumentou com a idade das áreas corroborando com alguns estudos na Floresta Atlântica (TOLEDO et al., 2002; PEZZATO, 2004; DICKOW, 2010). De acordo com a evolução da sucessão, as folhas apresentam menor esclerofilia, e os horizontes orgânicos tornam-se mais espessos, beneficiando o estoque de água e nutrientes (PINTO e MARQUES, 2003). As florestas tropicais são limitadas por $\mathrm{N}$ nas etapas iniciais da sucessão devido a maior ciclagem interna, ao passo que com o aumento da idade pelo aumento do estágio sucessional favorece um aumento gradativo das concentrações (DAVIDSON et al., 2007). 
Embora os teores de $\mathrm{P}$ tenham sido significativos foi observado que a variação para galhos, miscelânea e órgãos reprodutivos não teve relação com a idade das florestas secundárias. Observou-se aumento no teor de $\mathrm{P}$ na fração órgãos reprodutivos, exceto para a fração miscelânea em FS-4. A presença de uma substância fosforada no material de reserva (sementes) explica o aumento da quantidade de $P$ nesta fração que, por sua vez, devido a mobilidade do elemento no floema, é redistribuído dos órgãos mais velhos para os mais novos (NEVES et al., 2001).

Tabela 5 - Teores médios $\left(\mathrm{g} \mathrm{kg}^{-1}\right)$ de nutrientes nas frações de serapilheira depositada em seis áreas de floresta secundária, com diferentes idades e estruturas fitossociológicas, de Floresta Ombrófila Densa Submontana em Antonina, PR.

Table 5 - Mean values of nutrients in litterfall fractions deposited from six secondary forest areas, with different ages and phytosociological structures, in Brazilian Atlantic forest.

\begin{tabular}{|c|c|c|c|c|c|c|}
\hline Florestas secundárias & $\mathbf{C}$ & $\mathbf{N}$ & $\mathbf{P}$ & $\mathbf{K}$ & $\mathbf{C a}$ & Mg \\
\hline & \multicolumn{6}{|c|}{ Folhas } \\
\hline FS-1 & 449,6 & $20,8 \mathrm{ab}^{*}$ & 0,5 & 2,5 & $7,0 \mathrm{ab}$ & 1,5 \\
\hline FS-2 & 450,2 & $20,9 \mathrm{ab}$ & 0,5 & 2,9 & $9,5 \mathrm{a}$ & 1,2 \\
\hline FS-3 & 449,6 & $18,1 \mathrm{c}$ & 0,4 & 2,7 & $6,2 \mathrm{ab}$ & 1,8 \\
\hline FS-4 & 460,1 & $22,1 \mathrm{a}$ & 0,4 & 1,9 & $4,4 \mathrm{c}$ & 2,7 \\
\hline FS-5 & 451,8 & $19,2 \mathrm{bc}$ & 0,5 & 2,4 & $5,8 \mathrm{~b}$ & 2,3 \\
\hline \multirow[t]{2}{*}{ FS-6 } & 445,7 & $15,5 \mathrm{~d}$ & 0,5 & 2,3 & $9,1 \mathrm{a}$ & 1,6 \\
\hline & \multicolumn{6}{|c|}{ Galhos } \\
\hline FS-1 & 443,3 & $13,8 \mathrm{~b}$ & $0,4 \mathrm{~b}$ & $1,8 \mathrm{c}$ & 6,1 & 1,4 \\
\hline FS-2 & 444,8 & $15,1 \mathrm{ab}$ & $0,4 \mathrm{~b}$ & $1,9 \mathrm{c}$ & 8,8 & 1,6 \\
\hline FS-3 & 443,3 & $13,1 \mathrm{bc}$ & $0,3 \mathrm{~b}$ & $2,6 \mathrm{ab}$ & 5,6 & 1,4 \\
\hline FS-4 & 450,6 & $16,8 \mathrm{a}$ & $0,9 \mathrm{a}$ & $3,6 \mathrm{ab}$ & 6,6 & 4,1 \\
\hline FS-5 & 468,4 & $13,4 \mathrm{bc}$ & $0,9 \mathrm{a}$ & $3,8 \mathrm{a}$ & 5,7 & 2,1 \\
\hline \multirow[t]{2}{*}{ FS-6 } & 454,3 & $11,4 \mathrm{c}$ & $0,3 \mathrm{~b}$ & $2,2 \mathrm{bc}$ & 6,7 & 1,3 \\
\hline & \multicolumn{6}{|c|}{ Órgãos Reprodutivos } \\
\hline FS-1 & $451,2 \mathrm{~b}$ & $21,9 \mathrm{~b}$ & $0,9 \mathrm{a}$ & 3,8 & 5,6 & 1,4 \\
\hline FS-2 & $451,3 \mathrm{~b}$ & $20,9 \mathrm{~b}$ & $0,9 \mathrm{a}$ & 3,2 & 4,0 & 1,1 \\
\hline FS-3 & $451,2 \mathrm{~b}$ & $19,5 \mathrm{bc}$ & $1,5 \mathrm{a}$ & 2,9 & 3,3 & 1,6 \\
\hline FS-4 & $461,9 b$ & $24,5 \mathrm{a}$ & $0,4 \mathrm{~b}$ & 2,5 & 5,4 & 3,4 \\
\hline FS-5 & $465,0 \mathrm{~b}$ & $18,4 \mathrm{c}$ & $0,4 \mathrm{~b}$ & 2,5 & 5,6 & 2,3 \\
\hline \multirow[t]{2}{*}{ FS-6 } & 504,0 a & $14,4 \mathrm{~d}$ & $0,7 \mathrm{a}$ & 2,7 & 4,5 & 1,1 \\
\hline & \multicolumn{6}{|c|}{ Miscelânea } \\
\hline FS-1 & 436,6 & $22,5 \mathrm{~b}$ & $0,6 \mathrm{~b}$ & 2,7 & 7,4 & 1,7 \\
\hline FS-2 & 450,4 & $24,5 \mathrm{a}$ & $0,3 \mathrm{c}$ & 1,7 & 9,5 & 1,4 \\
\hline FS-3 & 436,7 & $21,0 \mathrm{bc}$ & $0,7 \mathrm{~b}$ & 3,1 & 6,4 & 1,7 \\
\hline FS-4 & 443,7 & $24,3 \mathrm{a}$ & $1,1 \mathrm{a}$ & 3,0 & 8,5 & 1,7 \\
\hline FS-5 & 457,9 & $19,8 \mathrm{~cd}$ & $0,8 \mathrm{~b}$ & 3,0 & 5,7 & 2,1 \\
\hline FS-6 & 442,8 & $18,1 \mathrm{~d}$ & $0,7 \mathrm{~b}$ & 2,6 & 8,5 & 1,5 \\
\hline
\end{tabular}

*Médias seguidas pela mesma letra (na coluna, dentro de cada fração nas áreas de floresta secundária) não diferem estatisticamente entre si pelo teste de Tukey a 5\% de probabilidade.

O teor de K na fração galhos foi inferior nas áreas mais avançadas e na área FS-6, fato atribuído à alta mobilidade do nutriente e a sua redistribuição no floema, além disso, a precipitação pode favorecer perdas do elemento por lixiviação antes da coleta da serapilheira. Caldeira et al. (2008) relatam que, pelo fato do $\mathrm{K}$ ser um cátion monovalente, a sua ciclagem solo-planta é mais rápida do que a de outros nutrientes.

A variação na concentração de $\mathrm{Ca}$ na fração folhas não foi relacionado com a idade das florestas secundárias e, nas demais frações, tanto na concentração $\mathrm{Ca}$ como na de $\mathrm{Mg}$ não houveram diferenças significativas. Os teores de $\mathrm{Ca}$ nas folhas corroboram com os estudos em 
Floresta Ombrófila Densa (BOEGER et al., 2005; SILVA e VILLELA, 2015). Machado et al. (2015) não encontraram diferença estatística para os teores de $\mathrm{Ca}$ em florestas em estágio sucessional intermediário, e nos teores de $\mathrm{Mg}$ em floresta de estágio inicial e avançado, relacionando que o maior acúmulo de nutrientes nas folhas e nas raízes ocorrem para a renovação em florestas iniciais e, ao fenômeno de imobilização de nutrientes no tronco com renovação mais lenta em florestas avançadas. Além disso, os teores de Mg foram mais baixos comparados aos valores encontrados por Scheer (2008) num trecho de Floresta Ombrófila Densa em Guaraqueçaba, PR avaliando nutrientes remanescentes na decomposição de serapilheira.

$\mathrm{O}$ aumento da idade nas florestas secundárias não conduziu a mesma sequência, tanto na restituição por frações, como no aporte anual dos macronutrientes. As frações de serapilheira adotaram a ordem crescente: miscelânea > folhas $>$ ramos > órgãos reprodutivos nas florestas secundárias mais desenvolvidas, e a sequência: folhas > miscelânea > ramos > órgãos reprodutivos nas demais florestas, igualmente encontrada por Bianchin (2013) em áreas de floresta secundária próximas a este estudo. $\mathrm{O}$ maior retorno de macronutrientes na fração miscelânea nas áreas mais desenvolvidas foi atribuído a quantidade anual depositada, principalmente em FS-2. De acordo com Araújo et al. (2006) devido a qualidade nutricional de folhas, esta fração é considerada o compartimento mais significativo da produção nas quantidades produzidas justificado pelo maior aporte na maioria das áreas.

Em geral, com exceção do $\mathrm{C}$, os elementos $\mathrm{N}$ e Ca são mais acumulados no solo na Mata Atlântica (Tabela 6). Com exceção da área FS-1, a sequência crescente de restituição por macronutrientes foi: $\mathrm{N}>\mathrm{Ca}>\mathrm{K}>\mathrm{Mg}>\mathrm{P}$ similar ao estudo de Caldeira et al. (2008) em Floresta Ombrófila Densa em Blumenau, SC. Já em FS1 a concentração de $\mathrm{Mg}$ foi superior a de $\mathrm{K}$ e $\mathrm{P}$ corroborando com os trabalhos de Britez (1994), Pinto e Marques (2003) em Floresta Atlântica do litoral paranaense; em fragmentos de Floresta Ombrófila Densa Montana na região norte fluminense do RJ (CUNHA et al., 2009); e, em Floresta Estacional Semidecidual na época chuvosa (CALDEIRA et.al., 2013). Diversos fatores influenciam na concentração de nutrientes na serapilheira, como a diversidade de espécies, parte do vegetal, bem como a sua posição na copa. A qualidade da serapilheira pouca alterada pode ter influência sobre a dinâmica anual de populações de organismos do solo e o fornecimento de nutrientes pode variar mais devido a sua quantidade produzida do que em função da sua qualidade (CUNHA et al., 1993).

Tabela 6 - Comparação do aporte de N, P, K, Ca e Mg na fitomassa depositada em florestas secundárias sob domínio de Florestas Ombrófilas Densa Submontana brasileiras.

Table 6 - Comparison of N, P, K, Ca e Mg in litterfall production deposited in secondary forests under the dominion of Brazilian Dense Ombrophylous Submontane Forests.

\begin{tabular}{|c|c|c|c|c|c|c|c|}
\hline \multirow{2}{*}{ Local } & \multirow{2}{*}{ Estágio sucessional } & \multicolumn{5}{|c|}{ Aporte de nutrientes $\left(\mathrm{kg} \mathrm{ha}^{-1}\right)$} & \multirow{2}{*}{ Referência } \\
\hline & & $\mathbf{N}$ & $\mathbf{P}$ & $\mathbf{K}$ & $\mathbf{C a}$ & Mg & \\
\hline \multirow{2}{*}{ Pinheiral, RJ } & Inicial & 116,0 & 5,0 & 50,0 & 89,0 & 29,0 & \multirow{2}{*}{ TOLEDO et al. (2002) } \\
\hline & Tardia & 219,0 & 6,0 & 67,0 & 108,0 & 38,0 & \\
\hline \multirow{3}{*}{ Blumenau, SC } & Jovem & 67,5 & 2,6 & 11,8 & 40,2 & 12,9 & \multirow{3}{*}{ CALDEIRA et al. (2008) } \\
\hline & Intermediário & 73,1 & 2,6 & 11,7 & 60,9 & 13,1 & \\
\hline & Avançado & 88,8 & 2,8 & 9,0 & 41,2 & 13,9 & \\
\hline \multirow{3}{*}{ Antonina, PR } & Inicial & 70,0 & 4,0 & 14,0 & 46,0 & 7,0 & \multirow{3}{*}{ DICKOW (2010) } \\
\hline & Média & 97,0 & 4,0 & 14,0 & 14,0 & 10,0 & \\
\hline & Avançada & 95,0 & 4,0 & 14,0 & 30,0 & 9,0 & \\
\hline \multirow{3}{*}{ Antonina, PR } & Menos desenvolvida & 116,0 & 5,0 & 13,0 & 33,0 & 23,0 & \multirow{3}{*}{ BIANCHIN (2013) } \\
\hline & Intermediária & 121,0 & 4,0 & 10,0 & 33,0 & 24,0 & \\
\hline & Mais desenvolvida & 153,0 & 5,0 & 14,0 & 42,0 & 25,0 & \\
\hline Antonina, PR & Madura & 164,4 & 8,4 & 19,2 & 32,3 & 15,5 & SLOBODA et al. (2017) \\
\hline
\end{tabular}


As áreas de florestas mais desenvolvidas proporcionaram o maior aporte anual de macronutrientes, sendo $\mathrm{Ca}, \mathrm{Mg}$ em FS-1 e P, $\mathrm{Mg}, \mathrm{K}$ em FS-2 (Figura 3). A floresta inicial, FS5 , aportou mais $\mathrm{N}$ devido à maior quantidade de serapilheira depositada nas estações verão e primavera. De tal modo, as florestas secundárias com maior idade contribuíram para o aumento no aporte de parte dos nutrientes avaliados. $\mathrm{O}$ acréscimo dos teores de alguns macronutrientes na serapilheira, à medida que aumenta o gradiente sucessional, além de estar relacionado às características morfológicas das folhas, está associado ao acúmulo de serapilheira sobre o solo (PINTO e MARQUES, 2003). Em comparação com outros estudos sobre aporte de nutrientes na Mata Atlântica, em diferentes tipologias florestais (Tabela 6) foram observados valores similares no aporte anual nos diferentes estágios de sucessão, com exceção das áreas tardias no estudo de Toledo et al. (2002) e no aporte de $\mathrm{N}$ em florestas maduras no estudo de Sloboda et al. (2017).
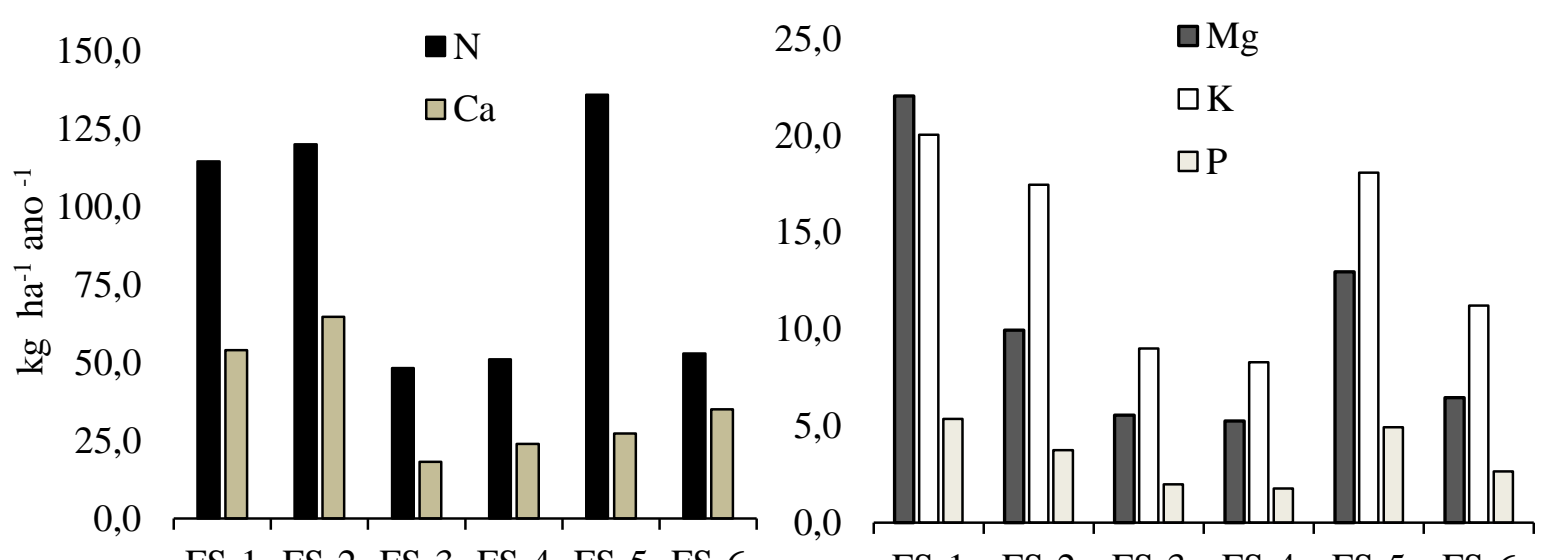

FS-1 FS-2 FS-3 FS-4 FS-5 FS-6

FS-1 $\quad$ FS-2 $\quad$ FS-3 $\quad$ FS-4 FS-5 FS-6

Figura 3 - Aporte de nutrientes em seis florestas secundárias, com diferentes idades e estruturas fitossociológicas, de Floresta Ombrófila Densa Submontana em Antonina, PR. Da esquerda para direita aporte de N e Ca, seguido de Mg, K e P, em amplitudes diferentes.

Figure 3 - Nutrients contribution in six secondary forests with different ages and phytosociological structures, in Submontane Dense Ombrophylous Forest in Antonina, PR. From left to right the contribution of $\mathrm{N}$ and $\mathrm{Ca}$, followed by $\mathrm{Mg}, \mathrm{K}$ and $\mathrm{P}$, in different amplitudes.

As quantidades totais de nutrientes depositadas foram 216, 216, 83, 90, 199 e $108 \mathrm{~kg}$ $\mathrm{ha}^{-1} \mathrm{ano}^{-1}$, respectivamente nas florestas secundárias. $\mathrm{O}$ aporte anual de nutrientes adotou a ordem: FS-1 e FS-2 > FS-5 > FS-6 > FS-4 > FS-3. Esse padrão de deposição de nutrientes foi observado em outros estudos envolvendo sucessão secundária de Floresta Atlântica (BARBOSA e FARIA, 2006; CALVI et al., 2009). Gomes et al. (2010) sugeriram que, devido maior diversidade de espécies ocorreu maior devolução de nutrientes ao solo em um dos fragmentos estudados na Floresta Ombrófila
Densa em Teresópolis/RJ com 23 ha.

Os aspectos fitossociológicos das florestas secundárias mais desenvolvidas, consideradas mais próximas do estágio clímax de sucessão vegetal e compreendendo a ciclagem de nutrientes (fase biogeoquímica) em ecossistemas florestais podem indicar o maior retorno de nutrientes contidos na fitomassa para o solo. Ainda, em solos altamente intemperizados, com poucas bases trocáveis, a serapilheira, via deposição, é o principal reservatório de nutrientes em florestas tropicais (NEVES et al., 2001). Além disso, segundo MARTINS (2009) a 
serapilheira é um parâmetro importante na avaliação de restauração de áreas degradadas e perturbadas e, consequentemente, as estimativas de produção de fitomassa especialmente em florestas secundárias, podem contribuir para o avanço de estudos nesse âmbito, bem como para a recomendação de espécies na recomposição de áreas (DICKOW et al., 2009) com o intuito de maior produção de serapilheira e retorno de nutrientes nas diferentes condições ambientais e nos estágios de sucessão secundária em que as florestas se encontram.

\section{Conclusões}

A idade e a estrutura fitossociológica das florestas não apresentaram um padrão na produção de serapilheira total e por frações. A maior deposição de serapilheira ocorreu nas estações primavera e verão ocorrendo maior deposição foliar nas áreas secundárias.

As florestas secundárias mais desenvolvidas tiveram o maior aporte anual de $\mathrm{Ca}, \mathrm{Mg}, \mathrm{K}$ e $\mathrm{P}$ em comparação com florestas intermediárias e menos desenvolvidas sendo que a fração miscelânea foi mais significativa na restituição de nutrientes.

\section{Referências Bibliográficas}

ARAÚJO, R.S. et al. Aporte de serapilheira e nutrientes ao solo em três modelos de revegetação na Reserva Biológica de Poço das Antas, Silva Jardim, RJ. Revista Floresta e Ambiente, v.12, n.2, p.16-24, 2006

BARBOSA, J. H. C.; FARIA S. M. Aporte de serrapilheira ao solo em estágio sucessionais florestais na Reserva Biológica de Poço das Antas, Rio de Janeiro, Brasil. Rodriguesia, v.57, n.3, p.461-476. 2006

BIANCHIN, J. E. Aporte de fitomassa e nutrientes em florestas secundárias da Mata Atlântica no litoral do Paraná. $102 \mathrm{f}$. Dissertação (Mestrado em Engenharia Florestal)
- Universidade Federal do Paraná, Curitiba, 2013.

BIANCHIN, J.E. et al. Deposição de Fitomassa em Formações Secundárias na Floresta Atlântica do Paraná. Revista Floresta e Ambiente [online], Seropédica, v.23, n.4, p.524-533, 2016.

BOEGER, M. R.; WISNIEWSKI, C.; REISSMANN, C. B. Nutrientes foliares de espécies arbóreas de três estádios sucessionais de Floresta Ombrófila Densa no Sul do Brasil. Acta Botânica Brasilica, v. 19, n.1, p.167-181, 2005.

BRITEZ, R.M. Ciclagem de nutrientes minerais em duas florestas da planície litorânea da Ilha do Mel, Paranaguá. 272 f. Dissertação (Mestrado em Ciência do Solo) Setor de Ciências Agrárias, Universidade Federal do Paraná, Curitiba, 1994.

BRAY, J. R.; GORHAM, E. Litter production in forests of the world. Advances in ecological research, 1964, v. 2, p. 101-157.

CALVI, G. P.; PEREIRA, M. G.; ESPÍNDULA JÚNIOR, A. Produção de serapilheira e aporte de nutrientes em áreas de floresta atlântica em Santa Maria de Jetibá, ES. Ciência Florestal, v. 19, n. 2, p. 131-138, 2009.

CALDEIRA, M. V. W. et al. Quantificação de serapilheira e de nutrientes - Floresta Ombrófila Mista Montana - Paraná. Revista Acadêmica, v. 5, n. 2, p. 101-116, 2007.

CALDEIRA M.V.W et al. Quantification of litter and nutrients on an Atlantic Rain Forest. Semina: Ciências Agrárias, v. 29, p.53-68, 2008.

CALDEIRA M.V.W. et al. Biomassa e nutrientes da serapilheira em diferentes coberturas florestais. Comunicata Scientiae, v.4(2), p.111-119, 2013. 
COSTA, C.C.A. et al. Análise comparativa da produção de serapilheira: em fragmentos arbóreos e arbustivos em área de catinga na Flona de Açu - RN. Revista Árvore, v.34, p.259-265, 2010.

CUNHA, G. C. et al. Dinâmica nutricional em Floresta Estacional Decidual com ênfase aos minerais provenientes da deposição da serapilheira. Ciência Florestal, v. 3, n. 1, p. 3564, 1993.

CUNHA, G.D.M. et al. Biomass, carbon and nutrient pools in montane atlantic forests in the north of Rio de Janeiro state, Brazil. Revista Brasileira de Ciência do Solo, v.33, p. 11751185, 2009.

DAVIDSON, E.A. et al. Recuperation of nitrogen cycling in Amazonian forests following agricultural abandonment. Nature, v. 447, p. 995-998, 2007.

DELITTI, W.B.C. Aspectos comparativos da ciclagem de nutrientes na mata ciliar, no campo cerrado e na floresta implantada de Pinus elliottii Engelm. var. elliotti, Mogi Guaçu, São Paulo. 298 f. Tese (Doutorado em Biociências) - Instituto de Biociências, Universidade de São Paulo, São Paulo, 1984.

DICKOW, K. M. C.; MARQUES, R.; PINTO, C. B. Lixiviação de nutrientes da serapilheira recém depositada em sucessão ecológica na Floresta Atlântica, Litoral do Paraná. Revista Floresta, v. 39, n. 1, p. 145-156, 2009.

DICKOW, K. M. C. Ciclagem de fitomassa e nutrientes em sucessão secundária na Floresta Atlântica, Antonina, PR. 215f. Tese (Doutorado em Engenharia Florestal) Universidade Federal do Paraná, Curitiba, 2010.

DICKOW, K.M.C. et al. Produção de serapilheira em diferentes fases sucessionais de uma Floresta Atlântica secundária, em Antonina, PR. Cerne, v.18(1), p.75-86, 2012.
DINIZ, S.; PAGANO, S. N. Dinâmica de folhedo em floresta mesófila semidecídua no município de Araras, SP. I - Produção, decomposição e acúmulo. Revista do Instituto Florestal, v. 9, n. 1, p. 27-36, 1997.

DOMINGOS, M. et al. Produção de serapilheira na floresta da Reserva Biológica de Paranapiacaba, sujeita aos poluentes atmosféricos de Cubatão, SP. Hoehnea, v.17, n.1, p.47-58, 1990.

FERRETI, A.R., BRITEZ, R.M. A restauração da Floresta Atlântica no litoral do estado do Paraná: os trabalhos da SPVS. In: GALVÃO A.P.M., SILVA, P. editores. Restauração Florestal: fundamentos e estudos de caso. Colombo: EMBRAPA Florestas; 2005.

GIÁCOMO, R. G. Fitossociologia, aporte de serapilheira, estoques de carbono e nitrogênio em diferentes formações vegetais na Estação Ecológica de Pirapitinga-MG. Dissertação (Mestrado em Ciências Ambientais e Florestais) - Instituto de Florestas, Universidade Federal Rural do Rio de Janeiro, Seropédica, 2009. 144 f.

GOMES J.M. et al. Aporte de serapilheira e de nutrientes em fragmentos florestais da Mata Atlântica. Revista Brasileira Ciências Agrária, v.5(3), p.383-39, 2010.

HAAG, H. Ciclagem de nutrientes em florestas tropicais. Campinas: Fundação Cargill, 1985. 144 p.

HINKEL, R. Aspectos da ciclagem de nutrientes de dois estádios sucessionais de Floresta Ombrófila Densa no Parque Municipal da Lagoa do Peri, Ilha de Santa Catarina, SC. 164f. Dissertação (Mestrado em Biologia Vegetal) - Universidade Federal de Santa Catarina, Florianópolis, 2002.

JACKSON, J.F. Seasonality of flowering and leaf-fall in a Brazilian Subtropical Lower 
Montane Moist Forest. Biotropica, 10(1): 3842. 1978.

JANZEN, D.H. Herbivores and the number of trees in tropical forests. American Naturalist v. 104:501-528, 1980.

LEIGH, E.G. Jr. Tropical Forest Ecology: A view from Barro Colorado Island. Oxford University Press. 1999.

LEITÃO FILHO, H.F. Ecologia da Mata Atlântica em Cubatão. São Paulo: Editora da Universidade Estadual Paulista; Campinas, SP: Editora da Universidade de Campinas, 1993. $184 \mathrm{p}$

MARQUES, R.; MOTTA, A.C.V. Análise química do solo para fins de fertilidade. In: LIMA, M.R. (Org.). Manual de diagnóstico da fertilidade e manejo dos solos agrícolas. Curitiba, Universidade Federal do Paraná, DSEA, p. 81-102, 2003.

MACHADO, D. L. et al. Ciclagem de nutrientes em diferentes estágios sucessionais da Mata Atlântica na bacia do Rio Paraíba do Sul, RJ. Bioscience Journal, v. 31, n. 4, p. 1222-1237, 2015.

MARTINS, A. P. L.; REISSMANN, C.B. Material vegetal e as rotinas laboratoriais nos procedimentos químico-analíticos. Scientia Agraria, v.8, n.1, p.1-17, 2007.

MARTINS, S. V. Recuperação de áreas degradadas: ações em áreas de preservação permanente, voçorocas, taludes rodoviários e de mineração. Viçosa, MG: Aprenda Fácil, 2009. 270p.

MEGURO, M.; VINUEZA, G.N.; DELITTI, W.B.C. Ciclagem de nutrientes minerais na Mata Mesófila secundária. Produção e conteúdo de nutrientes minerais do folhedo. Boletim de Botânica da Universidade de São Paulo, São Paulo, v. 7, p. 61-67, 1979.
NEVES, E. J. M.; MARTINS, E. G.; REISSMANN, C. B. Deposição de serapilheira e de nutrientes de duas espécies da Amazônia. Boletim de Pesquisa Florestal, n.43, p.47-60, 2001.

OLIVEIRA, R.R.; NETO, A.L.C. Produção de serapilheira e transferência de nutrientes em três estádios sucessionais sob manejo caiçara (Ilha Grande, RJ). In Anais... I Congresso da Sociedade Brasileira de Botânica, Blumenau, 1999.

O'NEILL, R.V. e DE ANGELIS, D.L. Comparative productivity and biomass relations of forest ecosystems. In Dynamic properties of forest ecosystems (D. Reichle, ed.) Cambridge University Press. Carmbridge, p.411-449, 1980.

PEREIRA, M.G.; MENEZES, L.F.T.; SCHULTZ, N. Aporte e decomposição da serapilheira na Floresta Atlântica, Ilha da Marambaia, Mangaratiba, RJ. Ciência Florestal, v.18, n.4, p.443-454, 2008.

PEZZATTO, A. W. Composição florística e ciclagem de macronutrientes em diferentes seres sucessionais de reservatório de hidrelétrica no Oeste do Paraná. 166 f. Dissertação (Mestrado em Ciências Florestais) Setor de Ciências Agrárias, Universidade Federal do Paraná, Curitiba, 2004.

PINTO, C.B.; MARQUES, R. Aporte de nutrientes por frações da serapilheira em sucessão ecológica de um ecossistema da Floresta Atlântica. Revista Floresta, v.33, n.3, p.257-264, 2003.

PROCTOR, J. Tropical forest litterfall. I. Problems of data comparison. In. Tropical rain forest: ecology and management. (S.L. Sutton, T.C. Whitmore e A.C. Chadwick, eds.). Blackwell Sci. Publi. Oxford, p.267-273, 1983.

PROTIL, C. Contribuição de quatro espécies arbóreas ao ciclo biogeoquímico em Floresta 
Atlântica na planície litorânea do Paraná. 127f. Tese (Doutorado em Engenharia Florestal) - Setor de Ciências Agrárias, Universidade Federal do Paraná, Curitiba, 2006.

RIBEIRO, M.C. et al. The Brazilian Atlantic Forest: How is left, and how is the remaining forest disturbed? Implications for conservation. Biological Conservation, v.142, p.1141- 1153, 2009.

ROCHA, A. A. Deposição de fitomassa e nutrientes, acumulação e decomposição de serapilheira em três tipologias da Floresta Atlântica, Paranaguá, PR. 113f. Dissertação (Mestrado em Ciência do Solo) - Setor de Ciências Agrárias, Universidade Federal do Paraná, Curitiba, 2006.

RODERJAN, C.V. et al. As unidades fitogeográficas do estado do Paraná. Ciência e Ambiente, v. 24, p.75-92, 2002.

SCHEER, M. B. Decomposição e liberação de nutrientes da serapilheira foliar em um trecho de floresta ombrófila densa aluvial em regeneração, Guaraqueçaba (PR). Revista Floresta, v. 38, n. 2, 2008 .

SILVA, M. F. F. Produção anual de serapilheira e seu conteúdo mineralógico em mata tropical de terra firme, Tucuruí-PA. Boletim do Museu Paraense Emílio Goeldi, Belém, v.1, n.1/2, p.111-158, 1984.

SILVA, F. de A. S. e; AZEVEDO, C. A. V. de. Versão do programa computacional Assistat para o sistema operacional Windows. Revista Brasileira de Produtos Agroindustriais, Campina Grande, v.4, n.1, p71-78, 2002.

SILVA, S. M.; BRITEZ, R. M. A vegetação da Planície Costeira. In: MARQUES, M. C. M.; BRITEZ, R. M. (Org.). História Natural e conservação da Ilha do Mel. Curitiba: Universidade Federal do Paraná, p.49-84. 2005.
SILVA, A.P. da; VILLELA, D. M. Nutrientes foliares de espécies arbóreas na Mata Atlântica: efeito do tamanho do fragmento. Ciência Florestal, v. 25(2), p. 317-325, 2015.

SLOBODA, B. et al. Litterfall and Nutrient Dynamics in a Mature Atlantic Rainforest in Brazil. Revista Floresta e Ambiente [online], Seropédica, v. 24, 2017.

SONGWE, N.C., FASEHUN, F.E., OKALI, D.U.U. Litterfall and productivity in a tropical rains forest, southern Bankundu forest, Cameroon. Journal Tropical Ecology, v4, p.25-37, 1988.

SPVS - Sociedade de Pesquisa em Vida Selvagem. 2005. Plano de manejo da Reserva Natural do Rio Cachoeira. Volume 1, Encartes I, II e III. 310 p.

TOLEDO, L. O. PEREIRA, M. G. MENEZES, C. E. G. Produção de serapilheira e transferência de nutrientes em florestas secundárias localizadas na região de Pinheiral, RJ. Ciência Florestal, v.12, n.2, p.9-16, 2002.

TOLEDO L.O., PEREIRA M.G. Dinâmica da deposição de serrapilheira em florestas secundárias do município de Pinheiral, RJ. Floresta e Ambiente; v. 11(1): 39-46, 2004.

VILELA, E. de A. et al. Espécies de matas ciliares com potencial para estudos de revegetação no alto Rio Grande, sul de Minas. Revista Árvore, v.17, n.2, p.117-128, 1993. 